Table 2. Toxicity of Component Salts of Preservatives to $P$. vaillantii STRAIN DFP 4443

\begin{tabular}{|c|c|c|c|}
\hline \multirow[b]{2}{*}{ Preservative } & \multicolumn{3}{|c|}{ Total inhibition point } \\
\hline & $\begin{array}{l}\text { 'Molal' } \\
\text { concentra- } \\
\text { tion }\end{array}$ & $\begin{array}{l}95 \text { per cent } \\
\text { fiducial } \\
\text { limits }\end{array}$ & $\begin{array}{l}\text { Percentage } \\
\text { of dry salt }\end{array}$ \\
\hline $\begin{array}{l}\mathrm{ZnSO}_{4} \cdot 7 \mathrm{H}_{2} \mathrm{O} \\
\mathrm{CuSO}_{4} .5 \mathrm{H}_{2} \mathrm{O} \\
\mathrm{Na}_{2} \mathrm{Cr}_{2} \mathrm{O}_{7} .2 \mathrm{H}_{2} \mathrm{O} \\
\mathrm{As}_{2} \mathrm{O}_{5}\end{array}$ & $\begin{array}{l}0 \cdot 59^{*} \\
0 \cdot 66 \\
0 \cdot 37 \\
0 \cdot 15\end{array}$ & $\begin{array}{l}0 \cdot 14-2 \cdot 53 * \\
0 \cdot 46-0 \cdot 92 \\
0 \cdot 27-0 \cdot 51 \\
0 \cdot 04-0 \cdot 48\end{array}$ & $\begin{array}{r}17 \cdot 0 \dagger \\
16 \cdot 5 \\
11 \cdot 0 \\
3 \cdot 4\end{array}$ \\
\hline $\left.\begin{array}{c}\mathrm{CuSO}_{4} .5 \mathrm{H}_{8} \mathrm{O}+ \\
\mathrm{Na}_{2} \mathrm{Cr}_{8} \mathrm{O}_{7} .2 \mathrm{H}_{2} \mathrm{O} \\
\mathrm{CuSO}_{4} .5 \mathrm{H}_{2} \mathrm{O}+\end{array}\right\}$ & $0 \cdot 33 \ddagger$ & $0 \cdot 16-0 \cdot 70 \ddagger$ & $18 \cdot 1 \S$ \\
\hline $\begin{array}{l}\mathrm{Na}_{2} \mathrm{Cr}_{2} \mathrm{O}_{7} \cdot 2 \mathrm{H}_{2}^{\prime} \mathrm{O}+ \\
\mathrm{As}_{2} \mathrm{O}_{5} \\
\text { Copper-chrome-- }\end{array}$ & $0 \cdot 25 \ddagger$ & $0 \cdot 15-0 \cdot 44 \ddagger$ & $19 \cdot 4 \S$ \\
\hline $\begin{array}{l}\text { arsenate preserva- } \\
\text { tive }\end{array}$ & - & $(16 \cdot 0-31 \cdot 6) \dagger$ & $23 \cdot 0 \S$ \\
\hline
\end{tabular}

- Gm. molecular weights added to $1,000 \mathrm{gm}$. of oven-dry sawdust. $\uparrow \mathrm{Gm}$. of dry (not anhydrous) salt added to $100 \mathrm{gm}$. oven-dry sawdust.

$\ddagger$ Concentration of each component.

\$ Total percentage of all components.

were tested as equimolecular mixtures. From the dosage-response relationships obtained, the total inhibition point (that is, the minimum concentration of preservative necessary to reduce the weight loss to zero) was computed for each preservative (Table 2). For any one preservative the amount of decay produced was approximately in inverse proportion to the logarithm of preservative concentration : some preservatives showed significant, though slight, deviations from this relationship, and these have been taken into account in calculating the fiducial limits given.

The resistance of strain DFP4443 to copper and zinc is even higher than would be expected from previous reports on the copper-tolerant species of Poria, and this strain is also highly tolerant of arsenic. Later tests, in fact, show it to be more tolerant than Lenzites trabea (Pers.) Fr., which is widely used as an arsenic-tolerant fungus in testing wood preservatives. It is presumably this high tolerance of arsenic which distinguishes the strains found here to be tolerant of copper-chrome-arsenates from the Poria strains used elsewhere in tests of these preservatives.

I wish to acknowledge the assistance of Messrs. L. Bartak and J. M. Stephenson in these investigations, which will be reported more completely at a later date.

$$
\text { E. W. B. DA Costa }
$$

Division of Forest Products,

Commonwealth Seientific and

Industrial Research Organization, Melbourne.

Dec. 12

${ }^{1}$ Carr, D. R., New Zealand Forest Service, Forest Research Institute, To 4 and supplement No. 1 (1955).

${ }^{2}$ Da Costa, E. W. B., and Rudman, P., Aust. J. Biol. Sci., 11, 45 (1958).

\section{Density-Dependent Factors in Ecology}

Andrewartha's ideas on density-dependent factors $^{2}$ in ecology are very misleading, and have already been criticized by Huffaker ${ }^{2}$. I wish to refer to three points which he raises in his recent communication. First, he argues that since the population models of Lotka and Volterra are based on densitydependent relationships, and these have been "partly confirmed by laboratory experiments with such simple animals as Paramecium, but not with more complex ones such as Calandra and Tribolium and not with any sort of animal in Nature", this is evidence against the applicability of ideas of density dependency. Yet density-dependent relationships are known to operate in two ways in Tribolium cultures. Chapman ${ }^{3}$ found the beetles ate their own eggs, and Boyce showed female beetles laid fewer eggs when crowded. The Lotka-Volterra formulæ have seldom been applied to interpret these happenings because they are not properly applicable to animals with a long pre-reproductive period. However, Crombie ${ }^{5}$ has used the formulæ with encouraging success to interpret the results of competition between the beetles Oryzaephilus and Tribolium and other grain insects.

Secondly, he quotes Nicholson's formula ${ }^{6}$ relating the equilibrium population density $N_{E}$ of an animal to its food supply $g$ :

$$
N_{E}=\frac{g-l g-w g}{q}
$$

where $l$ is the fraction of food lost to extraneous factors and $w$ the fraction wasted by surplus individuals which fail to mature, and $q$ the quantity of food required to complete development. By putting $w=0$ or 1 Andrewartha claims to 'solve' the equa. tion, whereas he is determining only the limits of possible solutions. Since $w$ is itself a function of the population density $N$, a solution can be obtained only if the appropriate function of $N$ is substituted for $w$. If, however, the competitive scramble for food wastes a negligible amount so that $w=0$, then $N_{E}=\frac{(g-l g)}{q}$, which has a simple biological meaning. Andrewartha's categorical assertion that "This does not satisfy the concept of an equilibrium density" seems to be a non sequitur.

I agree with Andrewartha that the experiment he outlines to test the action of density-dependent factors is unable to prove anything; but far better methods are available. Density-dependent factors can be identified by their observed effects at a variety of population densities, and their ability to reduce high populations either asymptotically or with damped oscillations to the equilibrium density can be checked.

For the idea of density-dependency to be useful, the idea must be properly understood. If factors are to be invoked to explain population stability, they must have certain well-defined properties?. To use the term inappropriately and in senses entirely different from the original definition causes nothing but confusion.

Department of Entomology,

$$
\text { G. C. VARLEY }
$$

University Museum, Oxford.

Jan. 27.

${ }^{1}$ Andrewartha, H. G., Nature, 183, 200 (1959).

2 Huffaker, C. B., Proc. Tenth Int. Congr. Entomol., 2, 625 (1958). ${ }^{3}$ Chapman, R. N., "Animal Ecology", 188 (MeGraw-Hill, 1931) - Boyce, J. M., Ecol., 27, 290 (1946).

SCrombie, A. C., Proc. Roy. Soc., B, 132, 362 (1945); 133, 76 (1946). - Nicholson, A. J., Aust. J. Zool., 2,9 (1954).

'Solomon, M. E., and Varley, G. C., Nature, 181, 1778 (1958).

ANDREWARThA ${ }^{1}$ has criticized an equation which he wrongly designates my "equation for intraspecific competition". Actually, it simply represents symbolically the necessary conditions for equilibrium in a postulated simple situation, other equations being given for other simple situations. His conclusion that "the equation is a tautology" is wholly due to his unjustifiable assumption that this equation is intended to represent the operation of competition. 